\title{
A Comparative Analysis of Clitoria ternatea Linn. (Butterfly Pea) Flower Extract as Natural Liquid pH Indicator and Natural pH Paper
}

\author{
Nur Faezah Syahirah, L., Muhammad Umar Lutfi, M.Y., Atika, A., Muhammad \\ Hafiz, R., Muhammad Zulhelmi, O.A., Mohd Ariff Adzhan, O. and Khor P.Y.
}

${ }^{2}$ Faculty Pharmacy \& Health Sciences, UniKL Royal College of Medicine Perak, Malaysia

(Received: 11 February, 2018; Accepted: 25 April, 2018; Published (web): 10 June, 2018)

\begin{abstract}
Clitoria ternatea Linn (CT) or Butterfly pea flower is a blue flower edible plant, which is commonly used as food colouring. The objective of this study was to develop a liquid and paper $\mathrm{pH}$ indicator from CT extracts. The effectiveness of $\mathrm{CT}$ extract as $\mathrm{pH}$ indicator was evaluated by titration and product testing result against standard indicator. The stability of CT extracts were also conducted in 7 days storage. Findings from this study shows that CT extract is an effective liquid $\mathrm{pH}$ indicator except for weak acid samples. Whereas $\mathrm{pH}$ paper made from $\mathrm{CT}$ extract is effective as $\mathrm{pH}$ paper except for testing $\mathrm{pH}$ range from $4-6$. It is concluded thatCT extracts can be potentially effective $\mathrm{pH}$ indicator.
\end{abstract}

Key words: Clitoria ternatea Linn., butterfly pea, $\mathrm{pH}$, indicator, titration, product testing.

\section{INTRODUCTION}

The $\mathrm{pH}$ indicator, also known as the acid-base indicator, is a weak acid or weak base which can show colour changes under different acidic and alkaline conditions. ${ }^{1}$ A commercially-available $\mathrm{pH}$ indicator in a liquid form is commonly used in titration to signal the completion of an acid-base reaction. This indicator may include phenolphthalein, bromothymol blue and methyl orange. A pH indicator also can be in the paper form and used to detect $\mathrm{pH}$ changes other than titrimetric analysis. This type of $\mathrm{pH}$ indicator includes the litmus paper and universal $\mathrm{pH}$ paper.

Commercialized indicators are typically composed of synthetic chemicals and they are produced through chemical treatment/process which can be potentially hazardous and they have the tendency to pollute the environment. In addition, they are not easily available and costly too. Thus, it can be

Correspondence to: Khor P.Y.

E-mail: pykhor@unikl.edu.my

Dhaka Univ. J. Pharm. Sci. 17(1): 97-103, 2018 (June) conclusively stated that there is a demand for a good source of natural indicator and hence it is worth while to do a relevant explorative study.

From literature review, it was noted that more than 50 pigment extracts originated from the plant source had already been investigated for their $\mathrm{pH}$ indication properties. ${ }^{2-6}$ The common solvent choice for the extraction is ethanol, methanol, water or its combination. Phenolphthalein is the most chosen standard indicator compared to methyl orange.

The natural indicator extracted from the plant source consists of anthocyanin, a subgroup of flavonoids. It is a secondary metabolite that contributes to blue, purple or red colours on fruits, leaves or flowers. ${ }^{7}$ Anthocyanin can react or interact with acids or bases, resulting in changes at the molecular level and hence the exhibition of colour changes (Figure 1 and 2).

For this study, we have used a local, common edible flower petal, Clitoria ternatea (CT) or butterfly pea flower as a natural source of indicator. ${ }^{3,8-10} \mathrm{CT}$ is a blue flower plant, which is able 
to produce anintense blue colour, which is commonly used as food colouring. Through this study, we have reported the effectiveness of CT flower extract in comparison: liquid versus paper $\mathrm{pH}$ indicator; and different acid-base strength combination and stability.

\section{METHODOLOGY}

Flower petal Clitoria ternatea Linn. A fully bloomed CT flower was purchased from the local market. The flower parts of CT were dried under shade. The green part of the sepal was cut and removed.

Colour pigment extraction. The extraction was performed with slightly modified method from Nyi Mekar Saptarini et al. (2015). ${ }^{3}$ The dried flower and water mixture (1:20) was heated to $35^{\circ} \mathrm{C}$ with pressing to obtain the maximum yield. ${ }^{10}$ After the extracted solution was filtered, testing at sections $\mathrm{A}$, $\mathrm{B}$ and $\mathrm{C}$ were done accordingly.

A: Development of natural liquid $\mathbf{p H}$ indicator from CT. A series of solutions from $\mathrm{pH} 1$ 14 was prepared from $0.1 \mathrm{~N} \mathrm{HCl}$ and $0.1 \mathrm{~N} \mathrm{NaOH}$. Digital $\mathrm{pH}$ meter and universal $\mathrm{pH}$ strips were used to ascertain the $\mathrm{pH}$ values. Two to three drops of CT extract was put in each $\mathrm{pH}$ solution to observe the colour change. The colour change was recorded to develop a liquid indicator colour scale for reference as the end point in titration analysis. Four sets of acid-base titration combinations were performed:

1. Strong acid/strong base (SA/SB);

2. Strong acid/weak base (SA/WB);

3. Strong base/weak acid (SB/WA); and

4. Weak acid/weak base (WA/WB).

Phenolphatein, a liquid indicator, was used as the standard for the titrimetric analysis. T-test was performed to compare the $\mathrm{pH}$ indication of liquid and $\mathrm{pH}$ paper.

B: Development of natural pH paper from CT. A qualitative filter paper was immersed in the CT extract for 3 - 5 minutes to ensure that the paper $\mathrm{pH}$ was fully saturated with the $\mathrm{CT}$ extract which was dried at room temperature. The coloured filter paper was then cut into strips as $\mathrm{CT}$ pH strips. A colour scale was developed by dipping the $\mathrm{CT} \mathrm{pH}$ strips prepared into a series of solution from $\mathrm{pH} 1-14$ (developed in Section A). The colour changes were observed and recorded as the $\mathrm{pH}$ scale. The effectiveness of the $\mathrm{pH}$ strips was examined in various product samples. The observed colour changes on the $\mathrm{CT} \mathrm{pH}$ strips were compared with the colour scale and universal $\mathrm{pH}$ paper to confirm the $\mathrm{pH}$ of the product tested.

C: UV-Vis spectroscopy and thin layer chromatographic analysis. Water extracts of CT (approximate $0.4 \mathrm{mg} / \mathrm{ml}$ ) were scanned ${ }^{8}$ through wavelengths 200-700 nm using UV-Vis spectrophotometer (Perkin Elmer, Lamda 35). The UV-Vis data were recorded. The liquid indicator colour scale developed in section A was spotted on the silica gel $\mathrm{GF}_{254}$ plate (Merck). TLC was developed in solvent system n-buthanol: glacial acetic acid: water (BAW) as recommended for anthocyanin extract. ${ }^{3}$ The patterns of chromatograms were observed.

Stability test. Stability tests were conducted for the CT extraction day 1 and day 7. The physical changes were observed, recorded and compared. The titration was conducted between the strong acid/strong base and weak acid/weak base combinations.

\section{RESULTS AND DISCUSSION}

In the present study, the blue pigment was extracted from the CT flower with the help of distilled water because water is the best medium for an acid-base titrimetric action. Anthocyanin, which is composed of hydroxyl and methoxyl group, is highly soluble in water, hence, provides a promising high yield; the water extract of CT has great thermal stability and so, it has the capability to withstand high temperature. $^{8}$

The anthocyanin content in the blue pigment was confirmed with the qualitative data from UV-Vis spectroscopy and thin layer chromatography. The CT extract showed multiple absorption peak in visible region, $527 \mathrm{~nm}-613 \mathrm{~nm}$ (Table 1a) and UV region, 223-250 nm (Table 1b). In the visible region, absorption band corresponding to the complementary colour of violet blue was observed. Whereas multiple 
peak in UV region was attributed to the multiple transitions from the ground state to the excited state of the molecule due to impure sample. ${ }^{11}$ In addition, absorption range of $223-250 \mathrm{~nm}$ also indicating transition electrons from lone pair and pi electrons to antibonding sigma and pi bond. ${ }^{11}$ This is consistent with the dominant group of hydroxyl, methoxy and benzene conjugated group in anthocyanin structures (Figure 1).

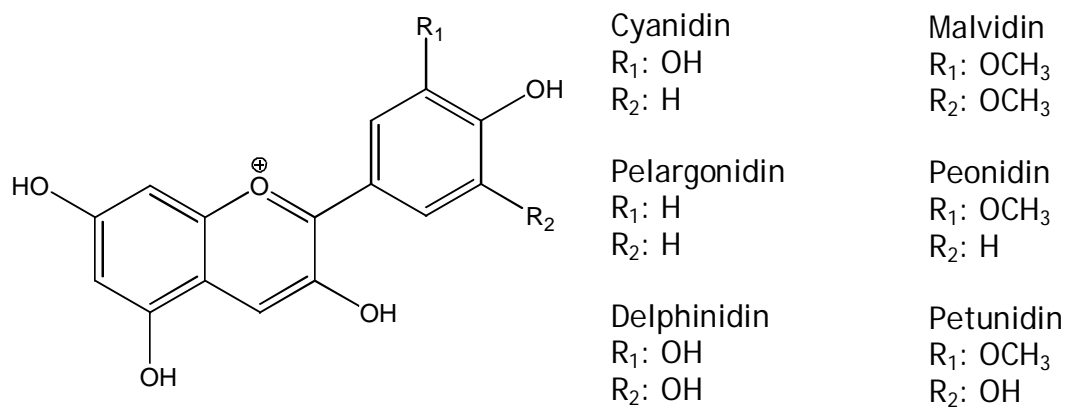

Figure 1. Structure of anthocyanins and its derivatives.

Table 1a. Wavelength $(\lambda)$ in $\mathrm{nm}$ and absorbance for CT aqueous extract by UV-visible spectroscopy (visible range).

\begin{tabular}{ccccccccc}
\hline$\lambda$ & 527.0 & 530.0 & 547.0 & 557.0 & 564.0 & 597.0 & 609.0 & 613.0 \\
\hline Abs & 0.645 & 0.000 & 0.729 & 0.446 & 0.541 & 0.895 & 0.406 & 0.532 \\
\hline
\end{tabular}

Table 1b. Wavelength $(\lambda)$ in nm and absorbance for CT aqueous extract by UV-visible spectroscopy (UV range).

\begin{tabular}{ccccccc}
\hline$\lambda$ & 223.50 & 227.0 & 231.0 & 233.98 & 238.92 & 242.99 \\
\hline Abs & 10.680 & 10.000 & 10.00 & 10.080 & 10.100 & 10.000 \\
\hline
\end{tabular}

The TLC chromatogram for the CT extracts in different $\mathrm{pH}$ conditions are shown in table 2. Two spots with Rf. 0.47 and Rf. 0.59 were observed for all the $\mathrm{pH}$ conditions. In comparison to the TLC chromatogram for the CT extract (Table 2), three spots were observed, with Rf. $0.36,0.47$ and 0.59 respectively. This result indicates that the colour changes in solvent $\mathrm{pH} \mathrm{1-14}$ are contributed by the same chemical constituent as it was from the CT extract. The elution pattern was the same with the previous study. ${ }^{3}$ The $R_{\mathrm{f}}$ value is closely related to the number of sugars attached to anthocyanin. ${ }^{12}$ Sugar is a polar compound and it tends to retain on the TLC plate in such a way that the higher number, the lower the $R_{f}$. The $R_{f}$ of 0.36 was not observed in TLC from pH 1 - 14; this could be due to the fact that the concentration of anthocyanin was too low for the compound separated to be observed or noted.

The recommended BAW solvent for elution is in the ratio of $5: 1: 4 .^{12}$ In this study, the elution following this ratio was relatively slow, thus, the modification to the ratio of $5: 4: 1$ provides a better elution. The $\mathrm{R}_{\mathrm{f}}$ obtained in this study was 0.47 and 0.59 , respectively which indicated that that anthocyanin extract was from less polar or less sugar derivative or monoglycoside. ${ }^{12}$ The structure confirmation might need further isolation and characterization.

In the liquid indicator $\mathrm{pH}$ scale development, the CT extract show different colours under different $\mathrm{pH}$ conditions (Fig. 3). The colour varies from red in acidic solution to purplish to blue to green in mildly 
alkaline solution to yellow in a very alkaline solution. These changes of colour range are similar to red cabbage purple, corn flowers blue, and poppies red; these changes are characteristic of anthocyanin pigment. $^{2}$ Unlike some commercialized indicator, such as phenolphthalein, only two types of color changes observed (colorless or pink) in acid base titration. Phenolphthalein undergoes a structural rearrangement as a proton is removed from one of its phenol group as the $\mathrm{pH}$ rises (Figure 4). CT extract was able to show multiple colour changes due to more than one proton donation or acceptance group (Figure 2).<smiles>[R]c1cc(-c2oc3cc(=O)cc(O)c-3cc2O)cc([R])c1O</smiles>

A: Quinoidal base (Blue)<smiles>[R]C1=CC(C(=O)C(O)/C=C2/C(O)=CC(=O)CC2O)C=C([R])C1O</smiles>

C: Chalcone (Colorless)<smiles>[R]c1cc(C(=O)/C(O)=C\C2C(=O)C=C(O)C=C2O)cc([R])c1O</smiles>

$\mathrm{AH}^{+}$: Flavilium cation (red)<smiles>[R]c1cc(C2(O)OC3=CC(O)C=C(O)C3C=C2O)cc([R])c1O</smiles>

B: Pseudobase or carbinol (Colorless)

Figure 2. Structural changes of anthocyanins in different $\mathrm{pH}$ conditions.

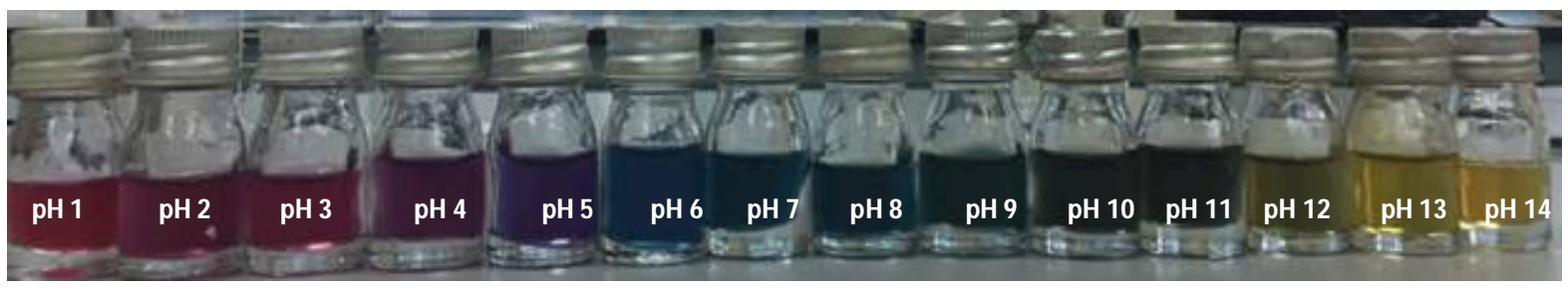

Figure 3. Color of CT extract in different $\mathrm{pH}$ condition. 
Table 2. Rf value for different $\mathrm{pH}$ conditions.

\begin{tabular}{lccc}
\hline Description & First spot & First spot $\left(\mathrm{R}_{\mathrm{f}}\right)$ & Second spot $\left(\mathrm{R}_{\mathrm{f}}\right)$ \\
\hline 3 Drops extract in solution from pH 1 - 14 & - & 0.47 & 0.59 \\
\hline Flower extract only & 0.36 & 0.47 & 0.59 \\
\hline
\end{tabular}

Table 3. Comparison of end point in titration with $\mathrm{CT}$ indicator and phenolphthalein.

\begin{tabular}{lcccc}
\hline Description & CT extract & Phenolphthalein & $\begin{array}{c}\text { T-test } \\
\text { ( -value })\end{array}$ & $\begin{array}{c}\text { Color change in } \\
\text { extract }\end{array}$ \\
\hline $\begin{array}{l}\text { Strong base vs strong acid } \\
(\mathrm{NaOH}, 0.1 \mathrm{M} \text { vs } \mathrm{HCl} 0.1 \mathrm{M})\end{array}$ & $6.27 \pm 0.06$ & $6.20 \pm 0.17$ & 0.56 & Red to blue \\
\hline $\begin{array}{l}\text { Weak acid vs weak base } \\
\left(\mathrm{CH}_{3} \mathrm{COOH}, 1 \mathrm{M} \text { vs NH}\right.\end{array}$ - $\left.1 \mathrm{M}\right)$ & $1.90 \pm 0.17$ & $2.00 \pm 0.17$ & 0.52 & Pale green to blue \\
\hline $\begin{array}{l}\text { Strong acid vs weak base } \\
\left(\mathrm{HCl}, 0.5 \mathrm{M} \text { vs } \mathrm{NH}_{4} \mathrm{OH}, 1 \mathrm{M}\right)\end{array}$ & $4.13 \pm 0.12$ & $4.47 \pm 0.06$ & $0.01^{*}$ & Red to blue \\
\hline $\begin{array}{l}\text { Weak acid vs strong base } \\
\left(\mathrm{CH} \mathrm{COOH}_{3} \mathrm{M} \text { vs NaOH } 0.5 \mathrm{M}\right)\end{array}$ & $2.47 \pm 0.06$ & $2.83 \pm 0.35$ & 0.15 & Green to blue \\
\hline $\mathrm{P}<0.05$ & & & &
\end{tabular}

Table 4. pH paper from CT extract on product testing.

\begin{tabular}{lccc}
\hline Product & Color change & CT extract pH paper & $\begin{array}{c}\text { Universal pH paper } \\
\text { (Standard) }\end{array}$ \\
\hline $\begin{array}{l}\text { Soup detergent, toothpaste, facial } \\
\text { cleanser, body wash, lotion }\end{array}$ & Blue remained & 7 & 7 \\
\hline Vinegar & Blue to red & 2 & 2 \\
\hline Soda bicarbonate & Blue to green & 10 & 10 \\
\hline Acne care cream & Blue to purple & 4 & 3 \\
\hline
\end{tabular}

Table 5. The physical and chemical stability test result.

\begin{tabular}{lll}
\hline Extract & Day 1 & Day 7 \\
\hline Color & Blue & Blue \\
Odor & Herbal odor & Change to unpleasant odor \\
Texture & Watery & Slimy \\
\hline
\end{tabular}

Table 6. Comparison of titration result from stability test on day-1 and day-7.

\begin{tabular}{lcccc}
\hline Description & CT Extract & Phenolphthalein & $\begin{array}{c}\text { T-test } \\
\text { ( p-value) }\end{array}$ & $\begin{array}{c}\text { Color change in } \\
\text { extract }\end{array}$ \\
\hline $\begin{array}{l}\text { Strong base vs strong acid } \\
(\mathrm{NaOH}, 0.1 \mathrm{M} \text { vs } \mathrm{HCl} 0.1 \mathrm{M})\end{array}$ & $5.20 \pm 0.20$ & $6.20 \pm 0.17$ & 0.041 & Red to blue \\
\hline $\begin{array}{l}\text { Weak acid Vs weak base } \\
\left(\mathrm{CH}_{3} \mathrm{COOH}, 1 \mathrm{M} \text { vs NH} \mathrm{N}_{4} \mathrm{O}, 1 \mathrm{M}\right)\end{array}$ & $2.35 \pm 0.07$ & $2.00 \pm 0.17$ & 0.015 & Pale green to blue \\
\hline
\end{tabular}

$* \mathrm{p}<0.05$ 
The colour changes are mainly due to the donation and acceptance of a proton from hydroxyl and methoxyl group in the structure of anthocyanin. ${ }^{7}$ In the CT blue extract (as a weak acid), it donates a proton to $\mathrm{OH}^{-}$ions in the water, forming anion under the alkaline solution, forming the base-form, $\mathrm{Bb}$ which is greenish. Hence, the point at which the colour changes from intermediate blue to greenish gives much information on reaching the equivalent point in a neutralization reaction.

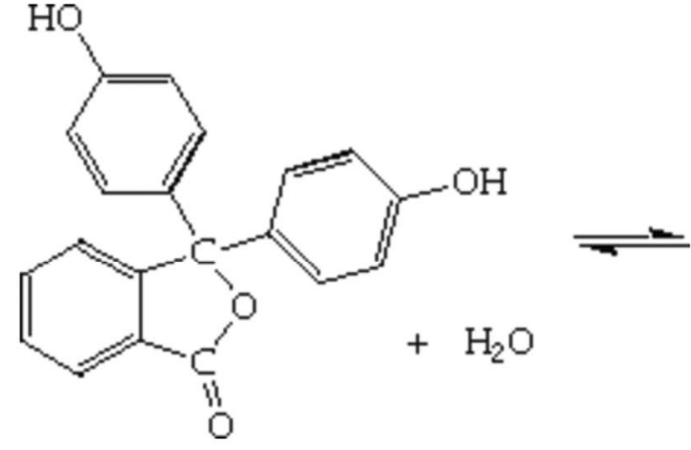

Colourless (acid)

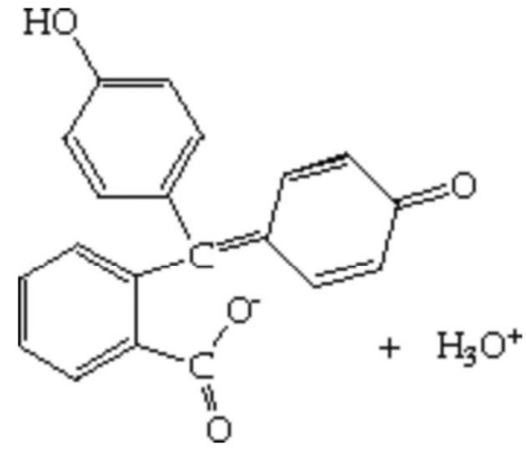

Pink (base)

Figure 4. Structural rearrangement of phenolphthalein under $\mathrm{pH}$ changes.

From the titration result observed by using phenolphthalein as the standard indicator, all the combinations of titration showed no significant difference $(\mathrm{p}<0.05)$ between the end point determined by the CT liquid indicator and phenolphthalein (Table 3). The CT extract showed sharp colour changes to blue upon reaching the end point of titration and this is easy to observe. However, in the strong acid and weak base titration, there is a significant difference between both indicators $(p>0.05)$ (Table 3$)$. In a slightly excess of titrant, the solution turned into red and over to the shoot end point. This is because the strong acid, which fully dissociates even at a low concentration, has higher capacity to react with the weak base. This problem can be overcome by further reducing the molarity of the titrant used.

It has been found that there is a limitation on the CT liquid indicator when titrant is a weak acid. This is because the CT extract appears as purplish colour in a weak acid condition, which is very near to the blue colour as the end point; it is therefore hard to observe the colour change when performing titration. This, thus leads to titration error. So, this study suggests that the CT extract is a potential acid-base indicator only for an alkaline sample or strong acid sample.

The $\mathrm{pH}$ paper made from the CT flower gave an instant colour change when dipped in different product sample (Table 4). However, the colour change was not so obvious in $\mathrm{pH}$ ranges $4-6$, and the violet to blue colour was not easy to differentiate either. As for the product testing, it is likely to be inconvenient because when an opaque semi solid product is tested, the $\mathrm{pH}$ paper tends to be covered with the sediments of the product itself, hence the colour changes could not be observed clearly. However, this limitation is also observable in other commercially-available $\mathrm{pH}$ paper. Thus, different paper $\mathrm{pH}$ materials could be explored to overcome this limitation. We think that the inefficiency of the CT $\mathrm{pH}$ paper can be improved by improving the quality of the paper as the CT extract in liquid form could produce a promising outcome.

From the result of the stability test, it was noted that during the 7 days of storage in a refrigerator, the colour remained unchanged (Table 5). However, the odour and texture of the extract dropped in quality. In 
terms of the titration test, there is no significant difference between the strong acid/strong base and weak acid/weak base titration (Table 6). The only difference that can be observed is the colour changes are not as sharp as on day 1. This is due to the degradation or oxidation during the storage, causing the changes in the molecular structure of anthocyan in. This explains the displacement of $\mathrm{H}^{+}$.

\section{CONCLUSION}

Based on this research study, it can safely be concluded that the CT extract can potentially be a good $\mathrm{pH}$ indicator as it clearly causes a gradual change in colour over a wide $\mathrm{pH}$ range. In fact, the $\mathrm{pH}$ of a solution can be approximately identified when a few drops of the CT extract are added to the solution.

The physical condition of the CT extract actually showed light change on day 7 . However, this did not affect the end point titration indication. The CT extract is an effective liquid $\mathrm{pH}$ indicator as it is able to show rapid, accurate and sharp colour changes when reaching the end point of titration. Furthermore, this liquid $\mathrm{pH}$ indicator was found to be good when the sample of analysis was not from any weak acid.

Based on these findings, we recommend that to develop a CT extract $\mathrm{pH}$ paper, the qualitative filter paper should be changed to other types of paper which have better absorption capacity. In future study, apart from surveying other paper for making the paper $\mathrm{pH}$ indicator, $\mathrm{CT}$ can be expanded as indicator in other types of titration such as nonaqueous titration which is commonly used in assay of pharmaceutical products, however, very limited studies were conducted.

\section{Acknowledgements}

We are very grateful to laboratory assistant in the Faculty Pharmacy and Health Sciences for their excellent assistance in making this research a great success. A heartfelt appreciation is also due to late Prof. Dr. Mohd Syafiq bin Abdullah who still remains as a source of strength and inspiration to this researcher.

\section{REFERENCES}

1. Sharma, P., Gupta,R., Roshan,S., Sahu,S., Shukla, A. and Garg, A. 2013. Plant extract as a acid base indicators. Inven. Rapid: Planta Activa. 3, 3-5.

2. Padma, S.V. and Dhara, B. 2010. Rose anthocyanins as acid base indicators. Electron. J. Environ. Agri.c Food Chem. 9, 875-884.

3. Saptarini, N.M., Suryasaputra, D. and Nurmalia, H. 2015. Application of butterfly Pea ( Clitoria ternatea Linn) extract as an indicator of acid-base titration. J. Chem. Pharm. Res. 7, 275-280.

4. Okoduwa, S.I.R., Mbora, L.O., Adu, M.E. and Adeyi, A.A. 2015. Comparative analysis of the properties of acid-base indicator of rose (Rosa setigera), Allamanda (Allamanda cathartica) and Hibiscus (Hibiscus rosa-sinensis) Flowers. Biochem. Res. Int. 2015

5. Mohd, P., Khan, A. and Farooqui, M. 2011. Analytical applications of plant extract as natural pH Indicator: A Review. J. Adv. Sci. Res. 2, 20-27.

6. Rajewari, L.S., Moorthy, S.N. and Rajasckharan K.N. 2010. Extraction, purification and spectral properties of anthocyanins from sweet potato leaves. J. Rod. Crops 36, 250-256.

7. Castañeda-ovando, A., Pacheco-hernández, M.D.L., Páezhernández, M.E., Rodríguez, J.A. and Galán-vidal, C.A. 2009. Chemical studies of anthocyanins: A review. Food Chem. 113, 859-871.

8. Lee, P.M. and Abdullah, R. 2011. Thermal degradation of blue anthocyanin extract of Clitoria ternatea flower. IPCEE. 7, 49-53.

9. Nikijuluw C. 2013. Color characteristic of butterfly pea (Clitoria Ternatea L.) anthocyanin extracts and brilliant blue. Bagro Agricultural University.

10. Kamat, S.S. and Khairnar, B.S.V.D. 2016. Investigation on new natural colour acid violet from Clitoria ternatea Linn. J. Acad. Ind. Res. 5, 14-16.

11. Janssens, K. 2003. Handbook of Spectroscopy.

12. Harbone, J.B. 1998. Phytochemical Methods A Guide to Modern Techniques of Plant Analysis. 